\title{
Dinámica de los regadíos tradicionales en Castilla y León: el caso del Canal del Duero
}

\author{
Eugenio Baraja, Daniel Herrero y Fernando Molinero \\ Universidad de Valladolid \\ baraja@fyl.uva.es, danielherreroluque@gmail.com, molinero@fyl.uva.es
}

\begin{abstract}
Resumen. Pese a no tener la relevancia superficial ni haber suscitado el interés -en términos de estudios y valoraciones- que han alcanzado en otros ámbitos peninsulares, los regadíos históricos, tradicionales o concesionales del Duero presentan una notable singularidad. De raigambre medieval muchos de ellos, los restos de sus infraestructuras, de sus elementos hidráulicos, de sus tramas parcelarias, y, en suma, de sus configuraciones territoriales, han llegado hasta nuestros días en una dinámica variable que se mueve entre el abandono y la reincorporación funcional. En este último caso, la "refuncionalización" pasa por su adaptación a las nuevas dinámicas productivistas o su arrinconamiento como reductos de "hobby farming" en los entornos de las poblaciones. Otras piezas, sin embargo, subsisten en espacios caracterizados por el conflicto y la tensión que suscita la competencia de usos, como ocurre en los entornos urbanos de mayor dinamismo. El espacio de regadío generado en torno al Canal del Duero es ilustrativo de esta última dinámica.
\end{abstract}

Palabras clave: Regadíos tradicionales, Canal del Duero, conflictos, tensiones.

\begin{abstract}
Dynamics of the traditional irrigated lands in Castilla y León: the case of the Canal del Duero. Despite not having the superficial relevance or having raised the interest -in terms of studies and assessments- that have achieved in other regions of the Iberian Peninsula, the historical, traditional, or concessional irrigated lands of the Duero present a remarkable singularity. With medieval roots many of them, the remains of their infrastructures, of their hydraulic elements and of their land plots, -in sum, the heritage of their territorial model-, have survived to the present, with a variable dynamic that moves between the abandonment and the functional reintegration. In the latter case, the "re-functioning" passed by their adaptation to the new and productivist dynamics, or their cornering as redoubts of "hobby farming" in external fringes of the villages. Other parts, however, remain in spaces characterized by conflicts and tensions raised by the competing land uses, such as we can see in the urban environments, more dynamic. The irrigated area generated around the Canal del Duero is illustrative of this latter tendency.
\end{abstract}

Keywords: traditional irrigation systems, the Canal del Duero, conflicts and tensions.

\section{Introducción}

El Canal del Duero es una obra de finales del XIX concebida inicialmente para el abastecimiento de Valladolid, el principal núcleo urbano de la región Castellano-Leonesa. No obstante, sus aguas pronto se utilizaron para beneficiar $8.000 \mathrm{~h}$ de tierra de labor, generando un espacio de regadío integrado con la agroindustria y orientado al abastecimiento de hortalizas de temporada a la ciudad. Localidades cuyos términos se regaban con el Canal del Duero, como Laguna de Duero, Tudela de Duero..., eran conocidas históricamente como la "huerta" de Valladolid.

Cuando se cumple un siglo de la conclusión de sus últimas infraestructuras, esa relación histórica regadío - ciudad es muy diferente. La actividad agraria lentamente ha ido cediendo a la presión de otros usos más valorados económicamente o a las servidumbres que la moderna urbanización impone. Infraestructuras de comunicación, espacios industriales y la ocupación residencial, han restado protagonismo a los cultivos, generando no pocas tensiones y conflictos que se han saldado con la pérdida de una de las configuraciones territoriales más singulares, ricas y diversas de una región que proyecta una imagen de monotonía y extensividad en sus paisajes agrarios. Al tiempo, las infraestructuras hidráulicas intentan 
integrarse con poca fortuna en este nuevo marco urbano territorial. La presente comunicación trata de ilustrar los aspectos más significativos de esta dinámica.

\section{Un diálogo histórico desigual: de una trabazón funcional sólida a una consideración marginal}

El Canal del Duero se concibe y construye con una vocación clara: solucionar definitivamente el problema secular del abastecimiento de aguas a Valladolid. Un problema cuyos antecedentes Agapito Revilla constata en el siglo XV, y que a duras penas se va paliando durante los siglos XVI y XVII con soluciones de alcance notorio para la época y de gran interés patrimonial para el presente, como el viaje de aguas de Argales y la construcción de las Arcas Reales, o más o menos imaginativas, como el ingenio Zubiaurre para elevar el agua desde el Pisuerga (Bustamante y Caballero, 1991: 16).

Aun así, el abastecimiento para los 50.000 habitantes que tenía la ciudad en 1875 era sumamente difícil. Apenas se disponía de $180 \mathrm{~m}^{3}$ diarios, repartidos en cinco fuentes dentro de la población, y $420 \mathrm{~m}^{3}$ en fuentes situadas en los arrabales. El agua del Pisuerga también se utilizaba, pero había que transportarla por medio de carros o caballerías (Borregón, 1880: 2). El crecimiento urbano del XIX y los problemas de salubridad derivados de las carencias de abastecimientos, determinaron la necesidad de no posponer más una solución considerada en su momento como compleja y costosa, pero definitiva: acceder a las aguas del Duero.

Descartadas otras opciones, el RD de 1 de mayo de 1864 se autoriza la construcción de un canal derivado del Duero basado en un proyecto que fue progresivamente modificado para solucionar los problemas técnicos y económicos que jalonaban su desarrollo. Tras no pocos conflictos con las empresas concesionarias, finalmente las obras se iniciaron en 1880 , tomando el agua de una antigua presa que existía en el término de Quintanilla de Abajo, y seis años más tarde se inauguraba el Canal del Duero, y su red completa de canalización de agua para el abastecimiento urbano $(200 \mathrm{l} / \mathrm{s})$. Se iniciaba así una vinculación con la ciudad que persistirá hasta nuestros días.

No obstante, el abastecimiento no fue un negocio para las compañías de aguas (Bustamante y Caballero, 1991: 28 y 29), pero había otra opción que se desarrolló a partir de que entrara en juego otro actor, la Sociedad Industrial Castellana (SIC), con intereses muy diferentes: la transformación en regadío para poder cultivar remolacha azucarera en cantidad suficiente para abastecer su fábrica, Santa Victoria, ubicada en la capital vallisoletana entre las líneas del Norte y de Ariza.

El canal tenía caudal $(4.000 \mathrm{l} / \mathrm{s})$ y concesión suficiente para transformar, según cálculos de la época, 8.000 ha en regadío. Con todo, su estado no era el mejor, y las infraestructuras que harían posible la llegada del agua a las fincas, aunque contempladas en el Plan de Explotación, no solo estaban sin construir, es que ni siquiera estaban proyectadas. Desde este punto de vista, el canal se consideraba, y así constaba en los archivos de la SIC, como "obra inútil y de ningún provecho para el país". Las obras para generar las infraestructuras de riego se prolongaron durante la primera década del siglo XX, y no se pararon solo en la reparación de los tramos más deficientes del canal, o en la construcción de la red de acequias principales, sino que se acometieron obras en brazales y almorrones para que "ni un 
solo regante en los términos de Tudela de Duero y Laguna, necesitara construir un brazal de $200 \mathrm{~m}$ para tener agua dentro de sus tierras" (Rodríguez, 1911: 249).

Lentamente se va configurando un espacio de regadío desde Quintanilla de Abajo a Santovenia y Simancas, pero especialmente desarrollado en Tudela de Duero, Laguna de Duero y Valladolid, municipios que acaparaban el grueso de las transformaciones. A su amparo, avanza una agricultura novedosa en técnicas y orientaciones. Los secanos cerealistas, las josas de almendros y viñedos o los pastizales, fueron dejando paso a un cultivo industrial y mucho más intensivo, la remolacha azucarera, que a la postre dio carácter a estos espacios regados. Pero también sirvió para afianzar otros regadíos que contaban con una raigambre antigua, las huertas, que siempre estuvieron en conexión con el abastecimiento urbano y se beneficiaron con el Canal de caudales más fácilmente aprovechables y más seguros, consolidando su presencia y abriendo nuevos espacios para su implantación.

El Canal, con las infraestructuras auxiliares, se integra por esta vía, abastecimiento y producciones agrícolas industriales y huertas, con lo urbano, con su sociedad y con su economía. Y ello sin interferir ni generar conflictos "territoriales" ni con la capital ni con los núcleos por los que discurre. Es una relación funcional, armónica y complementaria en su desarrollo.

Un siglo más tarde, esa relación ha cambiado por completo. La ciudad se ha convertido en aglomeración. El crecimiento compacto ha dado paso a una expansión discontinua, que afecta en buena medida al resto de los núcleos por los que atraviesa el Canal. Los nuevos usos, la necesidad de espacio para las modernas formas de residencia, las infraestructuras necesarias para el funcionamiento de la aglomeración, los equipamientos... todo ello ha ido "consumiendo" el espacio que tradicionalmente ocupaban estos regadíos.

La función de abastecimiento persiste, pero se ha ampliado y diversificado. Las crecientes necesidades hacen que la concesión inicial $(200 \mathrm{l} / \mathrm{s})$, se tuviera que incrementar en 1962 hasta los $600 \mathrm{l} / \mathrm{s}$, llegando a los $1200 \mathrm{l} / \mathrm{s}$ en 1975. Ese mismo año se aprueba la toma de emergencia por similar cantidad de $1200 \mathrm{l} / \mathrm{s}$ y del mismo río, pero bombeándola en el término municipal de Laguna de Duero. A ello hay que agregar la toma del Pisuerga y del Carrión. La primera, de 800 l/s, y con concesión de 1975, tiene un carácter excepcional, solo utilizable en momentos en los que el resto de abastecimiento sea insuficiente. La segunda, un total de $1.250 \mathrm{l} / \mathrm{s}$, toma el agua en el ramal sur del Canal de Castilla.

Por otro lado, en los años sesenta a la antigua azucarera Santa Victoria se le agregó en la capital otra más, ACOR. Previamente (años treinta) se montó en la provincia la de Peñafiel, y más adelante, ACOR volvería a levantar una nueva fábrica en Olmedo. A todas ellas se suministró remolacha, en mayor o menor medida, desde los regadíos del Canal. Sin embargo, la crisis del negocio azucarero justificó su progresivo cierre. En el caso de la Santa Victoria, la SIC es absorbida, primero por la Compañía de Industrias Agrarias, y después integrada en uno de los principales grupos azucareros del país: Ebro, quien finalmente ceró sus instalaciones en 1997.

Las huertas históricas, poco a poco, también han ido desapareciendo o han buscado nuevos emplazamientos. Las más cercanas han sido expulsadas directamente por la presión urbanística en sus diferentes etapas, bien en forma de promociones, bien en forma de ocupaciones ilegales. La ruptura de los canales tradicionales de comercio directo amparados en la proximidad, ha hecho otro tanto. Los regadíos del Canal del Duero, no solo han mermado sustancialmente, también han perdido esa personalidad que los singularizaba. Ahora, 
los pocos que van quedando no se diferencian, en lo sustancial, de los públicos o privados que han promocionado durante todo el siglo en otras áreas de la región.

Su trama territorial, caracterizada por la parcelación y los pequeños predios, que se contraponen y conviven con la gran explotación (la granja) y la finca, también ha sido alterada. Las reformas técnicas, como la Concentración Parcelaria, ha roto el rico mosaico del parcelario histórico, favoreciendo al tiempo modernas formas de distribución del agua. Donde persiste lo hace conviviendo con las edificaciones, más o menos legales, construidas para el ocio o la residencia principal.

El proceso de urbanización ha sido arrogante con el Canal, particularmente en Valladolid. Su obra principal, el Canal propiamente dicho, subsiste empequeñecida y arrinconada, cuando no abiertamente atropelladada por modernas vías de comunicación (rondas, autovías y líneas de alta velocidad ferroviaria) que circunvalan la ciudad por el sur, este y norte. Sus infraestructuras secundarias, acequias, y sobre todo brazales y almorrones, han ido progresivamente degradándose al perder su función agraria y, ante la falta de voluntad para integrarlos en los nuevos trazados de la urbanización, se esquivan al contemplarse como una dificultad y un problema añadido.

Marginado o subsidiario en sus funciones tradicionales, el Canal y su espacio de regadío se debate entre el deterioro y la recuperación que pueden abrir las incipientes muestras de diálogo que se esbozan recientemente: bien revalorizándolo en su dimensión patrimonial, bien rescatando algunas funciones tradicionales adaptadas a los tiempos (los nuevos hortelanos), bien contemplándolo como espacio subsidiario a la urbanización, es decir integrado como ámbitos de esparcimiento, paseo, deporte, reposo... Esta, hasta ahora, ha sido la vía elegida.

\section{Procesos de configuración de un espacio de regadío entre el Duero, el Esgueva y el Pisuerga}

A lo largo de una centuria en el sector del tramo medio del Duero se ha configurado una de las piezas de regadío más singulares de Castilla y León. Nunca alcanzó a regar la superficie para el que fue diseñado y dotado de caudal, pero a mediados de los años cincuenta se encontraba en su plenitud productiva y alcanzaba su mayor extensión utilizando los sistemas de riego convencionales. El desarrollo de una ciudad moderna, con gran necesidad de espacio para la instalación de las industrias que consolidarían su crecimiento, generó los primeros conflictos en los sesenta. Las nuevas pautas del urbanismo difuso, con la consolidación de nuevas formas residenciales, equipamientos e infraestructuras, terminaron por relegarlo a su mínima expresión. Las imágenes que proporciona el conocido como Vuelo Americano de 1956-57; las del Vuelo Interministerial (IRYDA) entre 1977-83, y las recientes del PNOA 2010, permiten reconstruir, si bien de forma aproximada, esta evolución, al tiempo que sirven para ilustrar los procesos descritos.

\subsection{De los orígenes a la consolidación de un área regada plenamente integrada en el entorno urbano: $1900-1957$}

La presencia histórica del regadío en el entorno de Valladolid se puede constatar representaciones tan difundidas como los grabados de Franz Hogenberg Vallisoletum. Civitates Orbis 
Terrarum (George Braun,1572). El agua del subsuelo en esta confluencia de esguevas con el Pisuerga, no debía faltar: caudales subálveos, manantiales que fluían desde las terrazas, antiguos lechos fluviales...(García Fernández señala, de hecho, que Valladolid "estaba sobre las aguas"), y los artilugios de elevación mecánica, como las norias, eran ampliamente utilizados. Pero las huertas no solo abundaban en la periferia de la ciudad, también proliferaban en su interior. Los abundantes conventos que tenían su asiento en el solar urbano, con recintos generosos, tenían siempre un espacio con esa función. La imagen que proyecta el Plano de Ventura Seco de 1738, redibujado por Agapito Revilla, muestra esta situación. En el resto de núcleos el caso se repetiría a su escala, pero sin tanta entidad. A modo de ejemplo, Madoz (79) refiere, para el caso de Tudela de Duero, que el terreno fertilizado por este río y el Jaramiel es feraz y de buena calidad, y se habla de "fuentes de buenas aguas, particularmente en el ex priorato titulado del Duero" (un espacio donde siguen abundando las huertas actualmente).

Con todo, Valladolid no era una provincia donde el regadío proliferara a comienzos del siglo XX, como tampoco lo era, en general, la región del Duero. La Junta Consultiva Agronómica (1904) daba cuenta de esta situación: "De tan escasa importancia es el regadío en esta provincia, que sólo alcanza á unas 3.000 hectáreas de las 756.935 que mide su total superficie. Y eso que el cultivo de la remolacha azucarera lo ha aumentado algo durante los últimos años, pues antes se limitaba á muy pocas huertas en los alrededores de las poblaciones" (121). Entonces, como se ha indicado, el Canal del Duero ya estaba construido, y era una de las pocas obras hidráulicas (junto al de Castilla y el del Príncipe Alfonso) que merecían tal nombre en la región. No obstante, cuando lo adquiere la Sociedad Industrial Castellana, en 1900, el Canal solo servía al propósito de abastecimiento, pues el número de hectáreas regadas eran unas pocas decenas (de 70 a 80 h), necesitando diseñar y construir toda la red de distribución y realizar notables reparaciones en muchos tramos de los $51 \mathrm{~km}$ con los que cuenta.

Con notable esfuerzo económico, y durante toda la primera década del siglo XX, la SIC hizo las reparaciones necesarias y construyó una red de $40 \mathrm{~km}$ de acequias y más de $60 \mathrm{~km}$ de brazales (a excepción de la de Santovenia, que se construye algo más tarde). En total, el área dominada, o susceptible de ser regada, era de $8.000 \mathrm{~h}$ distribuidas de la siguiente manera: $1.000 \mathrm{~h}$ en el término de Tudela, regadas por el canal (acequia) Supletorio (800 h) y por la acequia de Valdelga $(200 \mathrm{~h}$ ); la acequia de Laguna permitía regar $800 \mathrm{~h}$ en Laguna de Duero, a las que se agregaban otras 200 h en su continuación hacia Puente Duero. $4.000 \mathrm{~h}$ en Valladolid, mediante la distribución de las acequias de Las Arcas Reales y de Valladolid, de la que parte la de Simancas, permitiendo el riego de otras 1.000 h; por último, el tramo final del Canal, al norte de la ciudad, se prolonga por la acequia de Santovenia para regar otras $1.000 \mathrm{~h}$.

Pero una cosa era la construcción de las infraestructuras y otra el riego en unos ámbitos donde la inercia de la agricultura de secano hacía del regadío una empresa difícil. De hecho, nunca se conseguirá regar la superficie dominada. Téngase en cuenta que la Junta Consultiva Agronómica en 1904, señalaba lo siguiente a propósito del Canal del Duero: "El Canal del Duero, del que sólo está concluida la parte destinada a surtir de aguas la capital, no tiene aún las acequias que han de distribuirlas en el riego de las $8.000 \mathrm{~h}$ que comprenden sus distintas zonas, y sólo las proporciona a precios convencionales para algunas propiedades de especial situación, siendo de desear se normalice este servicio con arreglo al plan aprobado" (122). Una vez construidas las acequias y brazales, Nicolás Rodríguez apuntaba que en 1910 se regaban 1.200 h con aguas del Canal, algo insólito si se tiene en cuenta que diez años atrás el riego era "completamente desconocido" en el país, y enfati- 
zaba el efecto demostración de los primeros riegos, pues los resultados obtenidos por los regantes están haciendo que "gran número de agricultores han solicitado y obtenido en estos últimos años concesiones de aprovechamiento de aguas para transformar sus fincas de secano en regadío, obteniendo excelente resultado a pesar de lo costoso que es elevar las aguas 10, 15 y más metros por medios mecánicos” (251).

En 1918, la Junta Consultiva daba cuenta de que en esta provincia "los aprovechamientos directos de los ríos, tienen alguna importancia, sobre todo el canal del Duero, que se eleva a 4.200 litros por segundo, regando solamente 1.600 hectáreas de las 8.000 para que fue concebido" (160).

De esta forma, lentamente y sin alcanzar nunca toda la superficie dominada, mediada la centuria el área de regadío del Canal se ha consolidado en una superficie que rondaría, aunque sin alcanzar, $5.000 \mathrm{~h}$. Es la cifra que se deduce de la información que facilita el Vuelo Americano de 1956-57 (fig. 1), donde se pone en evidencia la importancia que adquirió el regadío en las terrazas del sur de Valladolid y su prolongación, siguiendo el lecho mayor del Pisuerga por el suroeste, hasta Simancas. Beneficiado por las acequias de las Arcas Reales, Valladolid y Simancas, en este sector se concentraría más de la mitad de la superficie regada. Las acequias y brazales, flanqueados por su línea de álamos, dibuja una de las tramas territoriales más interesantes de los regadíos de la región. En este ámbito, existían fincas de gran tamaño, pertenecientes a la burguesía urbana, o bien explotaciones grandes, de agricultores fuertes, que practicaban una agricultura innovadora. La Granja Escuela Experimental Agrícola era una referencia en el conjunto, y otras granjas, de menor tamaño, se diseminaban por un parcelario regular, alternando con las casas de recreo que las familias pudientes utilizaban para pasar el verano. $\mathrm{Y}$ este hecho lo diferenciaba de otros modelos de regadío, como el practicado en sur de Laguna de Duero o Puente Duero, ya consolidados como sectores de huertas, donde las parcelas, de reducidas dimensiones, revelaban el dominio de un tipo de explotación de menor tamaño. Y las huertas, en este caso plagadas de frutales, también proliferaban en Tudela de Duero, tanto al sur del Canal (acequia de Valdelga) como al norte, en el entorno de la carretera de Villabáñez.

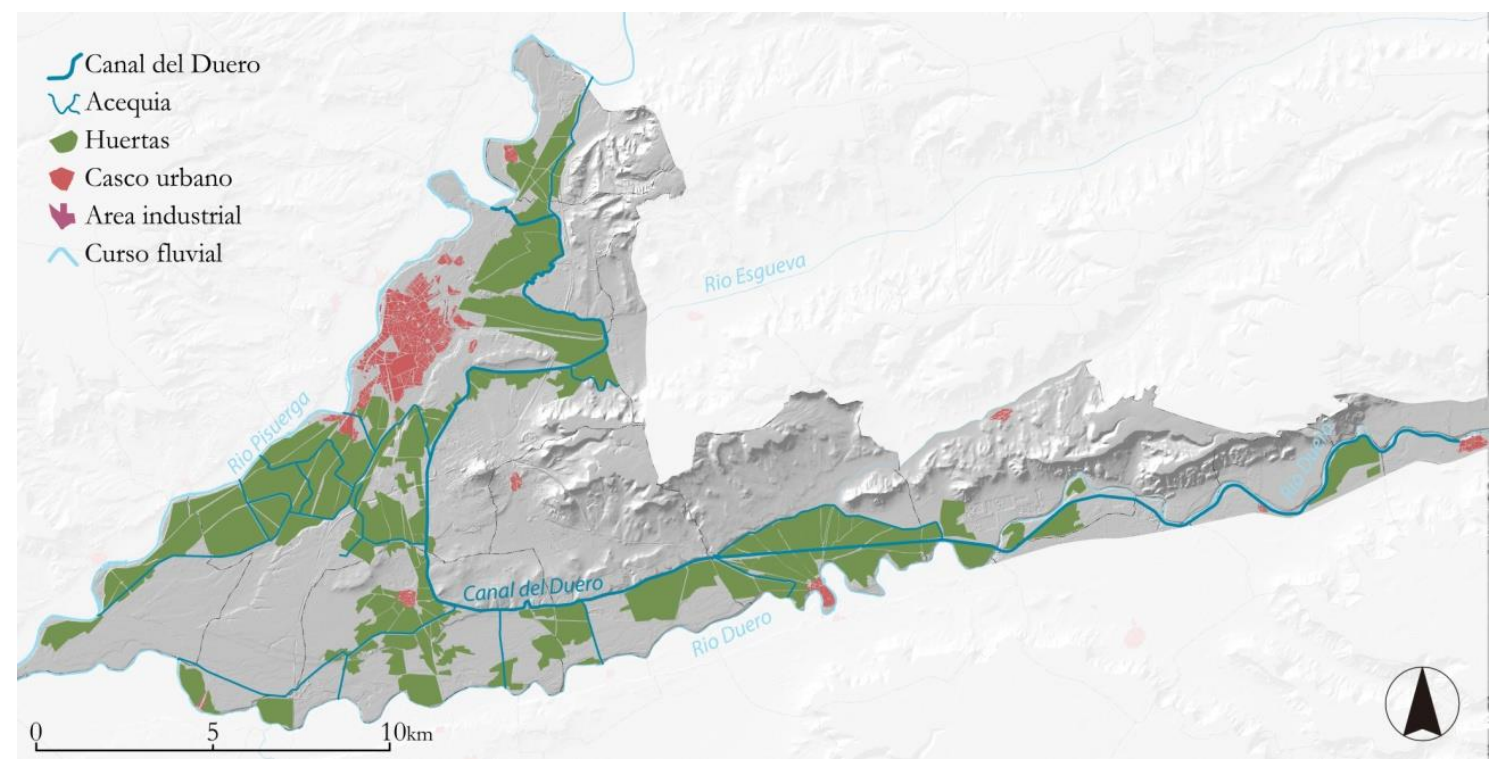

Fig. 1. Superficie regada con aguas del Canal del Duero (1956 - 1957). 
En todo caso, la interferencia con la ciudad era mínima, pues aunque es netamente receptora de emigrantes durante la primera mitad del siglo XX, la ciudad de Valladolid no había vivido un crecimiento urbano significativo. Según García Fernández, la ciudad tenía, a finales del siglo XIX una extensión de 382 h, y en 1931 ocupaba 461,94 h, es decir, había aumentado apenas $80 \mathrm{~h}$. Este mismo autor señala que el crecimiento de la ciudad tradicional permaneció inalterable durante mucho tiempo, y la ampliación y absorción de población se hizo "a base de núcleos de extrarradio, de desarrollo espontáneo que nacieron alejados del casco urbano" (García, 1974: 2 y 13). A la altura de 1956, la ciudad empieza a crecer, agrandándose otras 275 h (García, 1974: 66). Todos los núcleos de extrarradio anteriores experimentaron una expansión considerable: "Los del Sur, La Rubia, La Farola, prolongada por una lotificación de los años treinta (La Esperanza), Las Delicias y San Isidro se fusionan entre sí, y crecen también hacia el sur, a lo que contribuye el establecimiento en ellos de cuarteles, dependencias militares, almacenes e industrias"(García, 1974: 76). Por otro lado, los extrarradios se prolongan por calles con "caracteres de suburbio", mientras que los nuevos barrios que surgen entre los años cuarenta y sesenta tienen carácter de tales "la Cañada de Puente Duero, al sur de La Rubia; y el de la Bombilla en las proximidades de la carretera de Madrid (...) o el de Buenos Aires más allá del alto de San Isidro" (García, 1974: 77). No obstante, cuando se empieza a notar la interferencia con los espacios de regadío es en la fase de desarrollo posterior.

\subsection{E1 desarrollo urbano-industrial de Valladolid 1956-1980: competencia de usos y conflictos}

La superficie regada con aguas del canal del Duero no se incrementa prácticamente entre mediados de los cincuenta y finales de los setenta principios de los ochenta, fechas en las que se realizó el Vuelo Interministerial (IRYDA). De hecho la superficie regada sigue rondando las 5.000 ha Sin embargo, ya se han producido algunos cambios significativos, pues mientras merma en unos sectores se amplía en otros. El primer caso, tiene que ver con la competencia de usos del entorno de la ciudad de Valladolid. El segundo, con la incorporación de nuevas técnicas de aplicación del agua en el riego, como la aspersión, que permite ampliar el área dominada hacia terrenos más alejados y menos sistematizados (fig. 2).

La ciudad de Valladolid experimenta un fuerte crecimiento poblacional en estos años de emigración. Nutrida por importantes contingentes de población que llegan de todos los puntos de la región en las sucesivas oleadas de éxodo rural, la ciudad ha pasado de tener 150.959 habitantes en 1960 a 320.281 en 1981, y la superficie ocupa ya en los años setenta una extensión de 1.249 h. Este crecimiento superficial ha venido motivado, en parte, por la ampliación de barrios residenciales. Los antiguos núcleos de extrarradio se han fusionado con los suburbios de las décadas precedentes y también se ha ampliado el perímetro de la ciudad histórica, tanto por el sur como por el norte (García, 1974: 79). Las antiguas huertas ubicadas en los alrededores y próximas al continuo urbano se edifican (Delicias, Rondilla...), pero también se ven afectados algunos de los terrenos regados por el Canal, tanto en el este como en sur. Por tanto, como refiere García Fernández "el tipo de crecimiento urbano de Valladolid ha cambiado (...) la expansión en "mancha de aceite", que ya aparecía esbozada en las primeras fechas, se consagra plenamente" (1974: 78). Con todo, la afectación residencial es mínima si se compara con la competencia ejercida por las nuevas instalaciones industriales. 


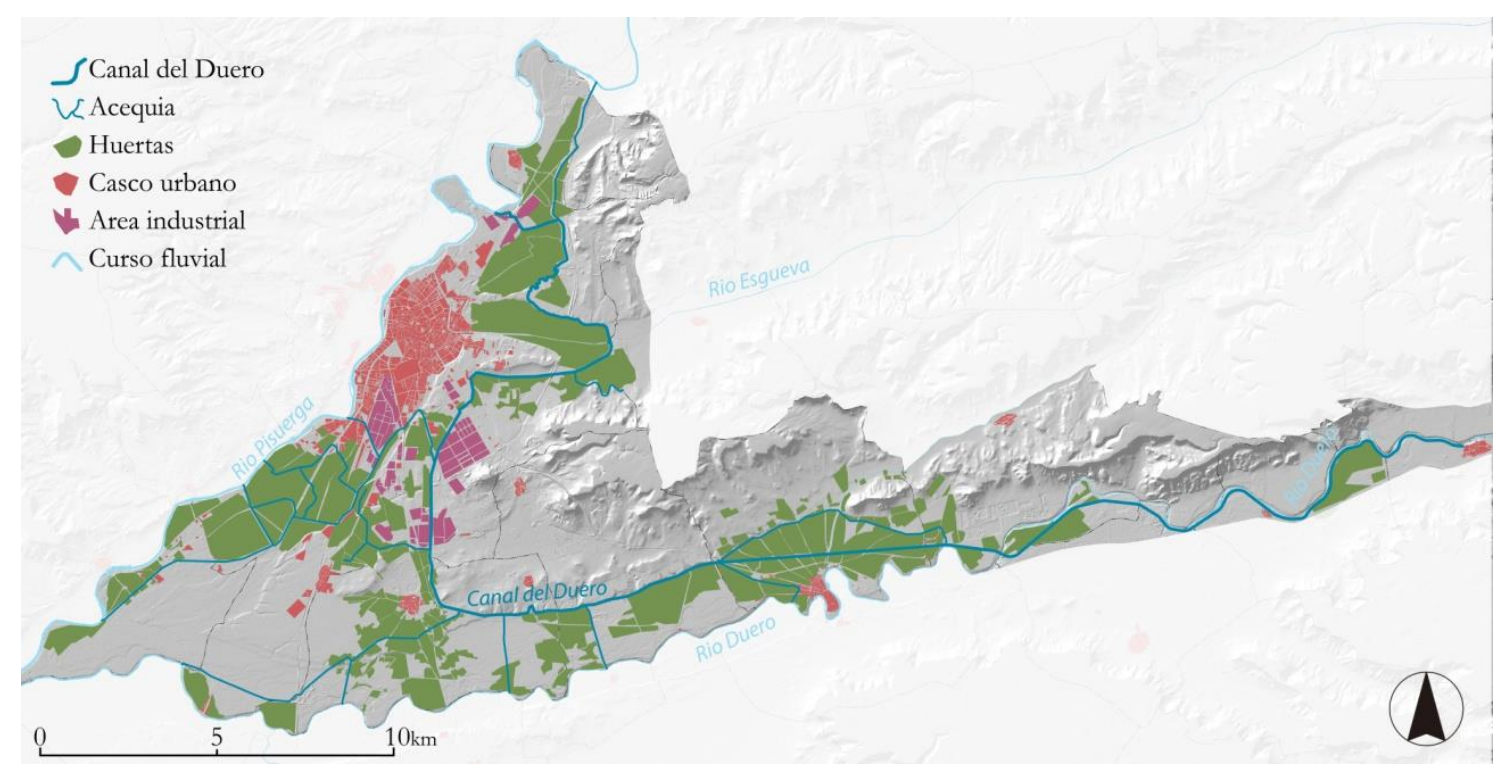

Fig. 2. Superficie regada con aguas del Canal del Duero (1977-1983).

$\mathrm{Y}$ es que la industria ha ocupado extensos lugares anteriormente regados. El proceso industrializador es, de hecho, el principal factor de desarrollo económico y social en los años sesenta, y a su impulso se subordina todo lo demás, incluido el espacio urbano y su entorno agrario. Por un lado, se trata de un tipo de industria que necesita mucho terreno para desarrollar su actividad productiva (automoción, química, alimentaria...). Por otro, su asiento, por lo general no planificado, muestra una clara preferencia por las vías de comunicación y los terrenos rústicos poco valorados.

Dejando al margen el sector de la margen derecha del Pisuerga, en el norte de Valladolid destaca la superficie que ocupan empresas como NICAS o ENDASA, si bien solo parcialmente restan espacio a los terrenos regados por el Canal del Duero. En el sur, entorno al Camino Viejo de Simancas, al tiempo que van apareciendo algunos almacenes, se esboza un pequeño atisbo industrial (quesos, piensos...), pero sin apenas continuidad por la alta valoración residencial que pronto adquiere este sector. Sin embargo, más hacia el este, en terrenos antes destinados al cultivo y beneficiados por el agua, aparece el único sector que responde a un proyecto de planificación: El Polígono Industrial de Argales. Este espacio ocupa $130 \mathrm{~h}$ enteramente sustraídas al espacio regado; a ellas hay que agregar otras $60 \mathrm{~h}$ del área industrial situada en la carretera de Madrid. Siguiendo esta carretera, y en los límites con Laguna de Duero, la empresa emblemática del sector de la automoción en Valladolid, Fasa Renault, junto a su pista de rodaje, ocupa otras 112 ha. Más adelante, ya en los setenta, el Canal del Duero dejará a su margen derecha otro gran sector industrial, el Polígono de San Cristóbal, pero su ubicación sobre la cota por la que discurre hará que solo una pocas hectáreas se vean afectadas. En conclusión, el desarrollo urbano de Valladolid en esta etapa, particularmente por su crecimiento industrial, restará unas $300 \mathrm{~h}$ a la superficie de riego.

Sin embargo, teniendo caudal para ampliar las concesiones, esa cantidad se verá compensada por el crecimiento del regadío en otros sectores del Canal. Municipios como Tudela de Duero o Laguna de Duero, también incrementan su población, y su desarrollo urbano se hará, en el primer caso, en mancha de aceite hacia el espacio comprendido entre la calle del Bosque y la de Villabáñez, teniendo como eje la antigua carretera de Valladolid, que, ahora desviada, fragmenta aún más el sector de la huerta comprendido entre el Duero y el 
canal homónimo. En alguna de estas promociones de casas bajas está presente la Obra Sindical del Hogar, como también en ocurrirá en Laguna de Duero, si bien su mayor entidad y proximidad a Valladolid hará que el crecimiento se oriente hacia el norte, edificando en el amplio espacio de pastos encharcadizos de la laguna que ahora se sanea. En estos municipios, el regadío aumenta en torno al centenar de hectáreas, si bien saliendo de los ámbitos tradicionales y ocupando las nuevas superficies que posibilita el bombeo y la aspersión: la margen derecha del canal Supletorio en el caso de Tudela y Villabáñez, o el sur y noroeste de Laguna. El mismo proceso se repite en otros núcleos (Santovenia, Cistérniga...).

Con todo, los cambios son más profundos. Ni la provincia de Valladolid ni la región han permanecido al margen de las grandes trasformaciones inducidas en la agricultura por los regadíos públicos y privados. Los del Canal del Duero, ahora, aparecen en muchos casos obsoletos frente a los que aprovechan aguas profundas, y en los que las modernas técnicas de captación y distribución permiten regar las fincas que la Concentración Parcelaria ha puesto a disposición de los agricultores. En el ámbito del Canal, se irá produciendo una diferenciación clara entre las explotaciones que poco a poco se modernizan, concentran sus parcelas, abandonan el riego por gravedad y utilizan técnicas de producción modernas (es decir, los que avanzan por el camino del productivismo), y los de huerta tradicional, que por sus singulares rasgos de propiedad, cultivos y localización, se colocan en una situación precaria, particularmente cuando también se rompen los canales de comercialización directa y la revolución de los trasportes les resta las ventajas de la proximidad.

Por otro lado, la ciudad crece y se industrializa. Las necesidad de agua en cantidad y calidad determinan que el Ayuntamiento, a la par que solicita un aumento de dotación $(600 \mathrm{l} / \mathrm{s}$ en 1962 y $1.200 \mathrm{l} / \mathrm{s}$ en 1975), busca nuevas fuentes de abastecimiento más seguras y fiables, pues el Canal, por diferentes motivos (fugas, reventones del tubo Barrasa, contaminación...) ya no puede garantizarlo. Asimismo, la SIC, que cuenta ya con otros ámbitos desde los que proveerse de materia prima para sus molinos, verá en el Canal del Duero una fuente de problemas y no pondrá objeciones a su enajenación. De esa debilidad arranca la marginalidad que se hará patente en la última fase.

\subsection{La marginalidad de los regadíos del Canal en el contexto de aglomeración: 1980 $-2010$}

La escasa consideración demostrada hacia estos regadíos tradicionales, construidos durante todo un siglo, se pone en evidencia en las dos últimas décadas del siglo pasado y la primera del actual, una vez superada la crisis y la atonía económica que se vivió en los años setenta del siglo XX. Se trata de una etapa, como señala García Fernández, paradójica, pues, ciñéndonos a la ciudad de Valladolid, el mayor crecimiento de la superficie urbana de su historia coincide con una fase en el que el número de habitantes se incrementa muy poco (se pasó de 320.281 habitantes en 1981 a 330.700 en 1991), o incluso desciende (315.522 habitantes en 2010). Asimismo, se trata de un crecimiento diferente, pues si hasta ese momento se ceñía al espacio urbano legado del pasado, desde mediados de los ochenta (PGOU de 1984) tendrá un carácter difuso, vertiendo su población en la superficie de los municipios de enderredor sin haber ocupado su propio término municipal, y mediante núcleos aislados y distanciados del continuo urbano (García, 2000:129). Este proceso tendrá gran significación en el sur, suroeste y sureste, afectando de lleno a la superficie regada con aguas del Canal, pues “... con la expansión de la segunda residencia en los años noventa, e impulsa- 
do por imperativos sociales de búsqueda del campo y de valores medioambientales, se ha dado el salto residencial al medio rural por Borde Sur, donde la ciudad contaba con mayores valores ecológicos y paisajísticos accesibles y lejos de entornos industriales en expansión (norte)" (Instituto de Urbanística UVa, 1998: 144). Por esta razón, el área regable disminuirá de forma significativa sin que ahora haya paliativos, y aunque la Comunidad de Regantes del Canal del Duero tiene concesiones para regar $4.478 \mathrm{~h}$, en realidad la superficie regada es mucho menor: entre 2.500 y 3.000 h. (fig. 3).

En los campos de cultivo regados por la Acequia de Valladolid, entre granjas, fincas (Minaya, Santa Ana...) y huertas tradicionales, con cierto alejamiento de la ciudad pero con buena accesibilidad a ella, los promotores inmobiliarios desarrollaron una estrategia de desarrollo a base de planes parciales que ofrecían un entorno residencial sustancialmente diferente al tradicional, de calidad, con viviendas unifamiliares de dos o tres plantas, edificadas entre medianerías con un pequeño espacio ajardinado (adosados), y donde Covaresa $(64,9 \mathrm{~h})$ en el entorno de la carretera de Rueda, fue su primera y mejor expresión, al representar "un nuevo tipo de crecimiento urbano ha quedado enteramente configurando como forma de expansión de la ciudad (García, 2000: 154). A este plan parcial de 1986, le seguirán otros que irán ocupando estos terrenos, soldándolos con el sur de la ciudad, y ampliándola por uno de los entornos más valorados: Camino Viejo de Simancas, Cañada de Puente Duero, Carretera de Rueda. Así, en sucesivos momentos se desarrollaron planes parciales como Parque Alameda, Paula López, Las Villas, Santa Ana, El Peral... Todo un conjunto residencial atravesado infraestructuras de notable impacto, como las rondas VA20 y VA-30.

Más al sur, y tras la solución de continuidad que introducen planes que, aún aprobados, la crisis económica ha paralizado (Las Riberas, que comprende 266, 7 h, y tiene una edificabilidad de 93,6 h), el proceso se repite en la zona dominada por la acequia de Simancas, en los terrenos de antiguas granjas y fincas de regadío (Entrepinos, Pinarillos...). A urbanizaciones concebidas como segundas residencias en los setenta y transformadas en residencias permanentes durante los ochenta como El Pichón y las Lagunillas (García, 2000: 263), les suceden, ya en los noventa y primeros años del presente siglo, otras (de entre 5 y $10 \mathrm{~h}$ ) como Las Aceñas o el Plantío Coto de Simancas,..., pero sobre todo Entrepinos, que con el campo de golf incluido ocupa $80 \mathrm{~h}$.

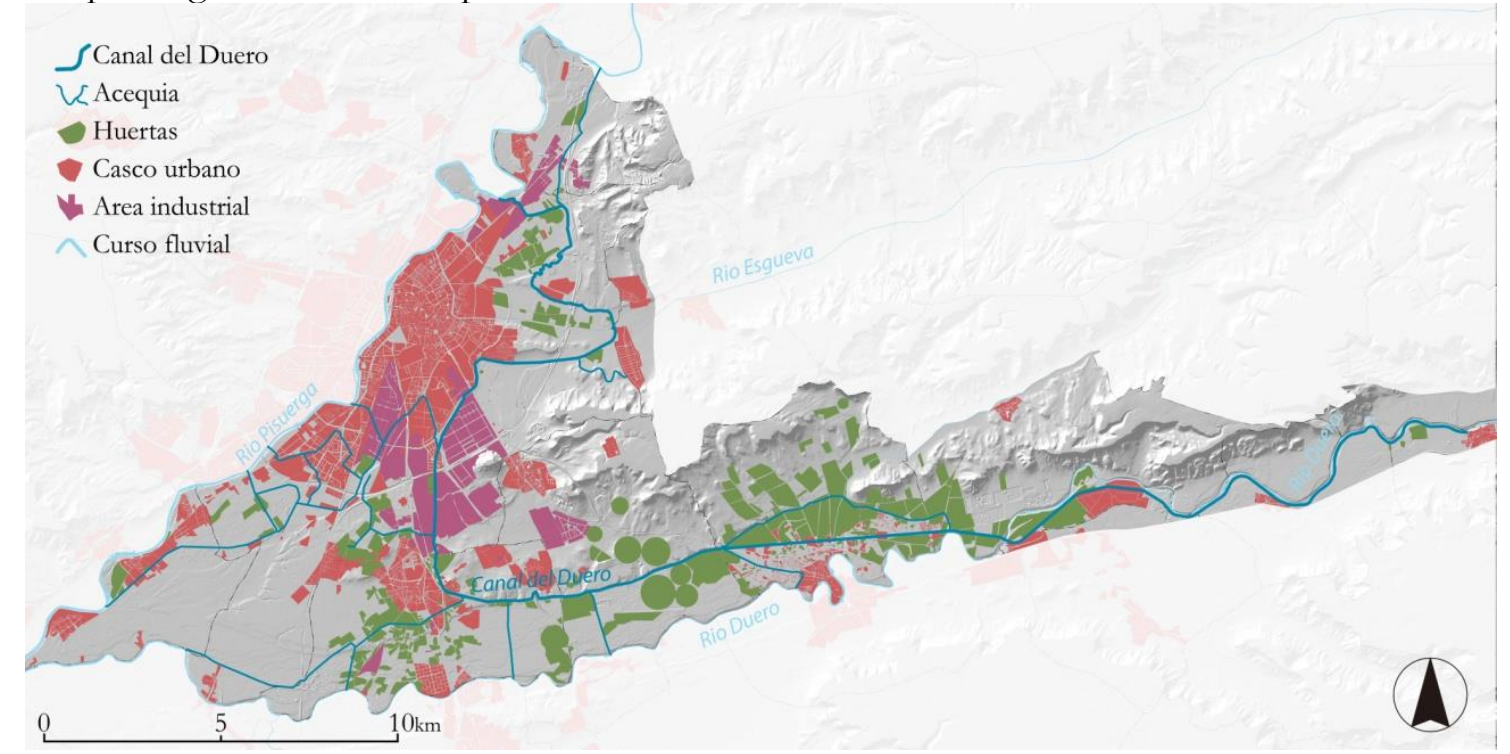

Fig. 3. Superficie regada con aguas del Canal del Duero. 2010. 
Al lado de usos residenciales, o de infraestructuras, en estos sectores tienen asiento instalaciones públicas, como dependencias municipales (depuradora, depósito de vehículos...), autonómicas (sede presidencial, PRAE Centro de Recursos Ambientales...), o equipamientos deportivos (CD Real Sociedad Hípica, hotel Lasa Sport...), educativos (varios colegios), así como viveros y otros establecimientos orientados a satisfacer la demanda de estas nuevas formas de vida.

Por todo ello, la mayor parte del sector regado por la Acequia de Valladolid y Simancas, a pesar de tener concesión, solo se riega ocasionalmente, permaneciendo amplios terrenos agrícolas en lleco y en expectativa de urbanización: en Simancas se tiene concesión para regar 108 h, sin embargo se riegan 32 h. En Valladolid, las concesiones ascienden a 1.215 h, pero apenas se riegan 370 , y de ellas prácticamente nada en este sector suroriental. Se puede decir que el regadío ha desaparecido de todo el sector comprendido entre la vía del Ave y el Pisuerga.

Con menor entidad, el proceso de urbanización avanza también en los regadíos del este de la ciudad. Los terrenos regados por la acequia de Valladolid se ven afectados por planes parciales como el de Arcas Reales, un conjunto residencial de 63 viviendas que afecta a 20 $\mathrm{h}$ regadas entre la citada acequia (enterrada durante $400 \mathrm{~m}$ ) y las industrias de la carretera de Madrid. En la acequia de las Arcas Reales, se dan situaciones más complejas, entre infraestructuras y dotaciones industriales. Aquí las rondas VA-20 y VA-30, así como el desvío del AVE (by-pass ferroviario), han tenido que habilitar puentes para unas acequias que dominan terrenos en manos grandes promotoras que o bien no han edificado o solo lo han hecho parcialmente. Así, al reclamo de nuevos equipamientos, como el centro hospitalario Pio del Rio Hortega, se desarrolla un sector emergente que comprendería el plan parcial Zambrana, sector 29, 5 h para 765 viviendas (que supone la unión con el barrio de Delicias); Canterac, con otras 845 viviendas; Pinar del Jalón, 41 h (14,5 residencial y 4,2 h industriales), y, sobre todo, la gran pieza del plan parcial la Florida, 46 h, entre la carretera de Madrid y la de Segovia, ejemplo de un sector que sigue en manos de grandes empresas inmobiliarias, en este caso DIURSA, donde se prevé edificar un total de 2.762 viviendas.

Por el noreste y norte, sin embargo, el desarrollo residencial ha sido menor (Los Santos Pilarica; Puertas de Casasola...), por lo que es el impacto de las infraestructuras (y sus proyectos logísticos asociados), así como el desarrollo de polígonos industriales, como en el caso de Las Panaderas, en Santovenia, lo que justificaría lo sustancial del impacto de la urbanización y el retroceso del regadío en este sector.

Pero Valladolid no solo ha crecido como ciudad, sino que se ha transformado en aglomeración, involucrando en su dinámica a los municipios cuyos términos benefician las aguas del Canal. Algunos, como Laguna de Duero o Tudela de Duero, los núcleos más importantes de la aglomeración, han experimentado un crecimiento de población verdaderamente espectacular (entre 1981 y 2010 se ha pasado de 6.393 habitantes a 22.110 en el primer caso, y de 4.537 a 8.746 habitantes en el segundo), y han ampliado la superficie dedicada a nuevas viviendas reproduciendo una dinámica similar a la descrita en el caso de Valladolid, de tal forma que el avance de las nuevas promociones afecta sustancialmente a los espacios de regadío que ven mermada de forma notable su entidad: Laguna de Duero tiene concesiones para regar $575 \mathrm{~h}$, y sin embargo solo riega $480 \mathrm{~h}$; Tudela $834 \mathrm{~h}$, cuando sus concesiones darían para regar $1.172 \mathrm{~h}$. 
Con todo existen diferencias entre ellos, pues mientras Laguna de Duero ha duplicado la superficie edificada de manera compacta, el caso de Tudela de Duero ilustra otro proceso que ha afectado en esta última etapa a los espacios del regadío del Canal del Duero: la urbanización ilegal. En efecto, el fenómeno de las segundas residencias, o residencias de ocupación temporal, como precisa García Fernández (2000:254), aunque cuenta con cierta tradición (Pinar de Antequera, Viana de Cega...), comienza a proliferar en los años sesenta. Asociado a un tipo de estatus social y de nivel de vida, cunde entre las clases acomodadas en forma de urbanizaciones de veraneo (La Corala, el Pinarillo, Coto del Cardiel, El Montico, La Morada, El Otero, Panorama...) permitiendo un modo de residencia cercano a lo rural sin renunciar al confort de lo urbano. Pero esta opción, no estaba al alcance de los menos pudientes, que recurrieron a la compra de pequeñas parcelas rústicas("terrenos") donde poder construir una casa, a veces un simple merendero, o aunar ésta con el ocio que proporciona el cultivo (chalé - huerta). Por ello proliferaron en las proximidades de las vías de comunicación, en los espacios de mayor calidad paisajísticas (pinares, huertas....), y allí donde las normas urbanísticas no se aplicaban estrictamente. Este fenómeno que vincula huerta y urbanización, aun no siendo desconocido en otros ámbitos, es más expresivo en Tudela de Duero, pues el PGOU redactado en 1991 solo se aplicó desde 1998, resultando que las construcciones ilegales han proliferado hasta cubrir buena parte de la huerta tradicional. Aquí lo podemos apreciar en los sectores que se extienden al oeste y al norte del municipio, tanto en las pequeñas parcelas regadas por la acequia de Valdelga (Camino de Valdelga), como en los "polígonos" que se dibujan entre la autovía A-11, el Canal, y los caminos que arrancan del núcleo original. Incluso al norte del Canal del Duero encuentran notable extensión en las inmediaciones del camino de Peñalba, y sobre todo, en los sectores de huerta tradicional que existían en las márgenes de la carretera de Villabañez, comprendiendo el espacio que enmarca el Canal Supletorio y el Canal del Duero.

\section{Conclusiones}

A falta de que se concreten nuevas formas de diálogo de la ciudad - aglomeración con los entornos agrarios de su alrededor, los procesos apuntados revelan la escasa sensibilidad habida con uno de los espacios de regadío más singulares de la región del Duero. No es algo genuino de la región ni de la aglomeración de Valladolid, pero tampoco se puede argumentar, como en otros ámbitos, falta de instrumentos de ordenación y planeamiento que no alertaran de su valor y apostaran por su integración. Por Decreto 206/2001, de 2 de agosto («Boletín Oficial de Castilla y León» de 8 de agosto de 2001) la Junta de Castilla y León aprobó las Directrices de Ordenación de ámbito subregional de Valladolid y Entorno. Un instrumento de ordenación que tenía por objeto la planificación del área urbana integrada por la ciudad de Valladolid y 22 términos municipales de su entorno, mediante la consideración conjunta y coordinada de sus problemas territoriales, en especial en cuanto a sus recursos, infraestructuras y equipamientos" (BOCyL, No 94, 19 de mayo de 2004, 6735). La calidad técnica y el alto rigor con la que fueron elaboradas, al plantear la figura de las Áreas de interés Paisajístico, Histórico y Agrícola (APHA) para los espacios más valiosos vinculados al Canal del Duero, como son los meandros del Pisuerga y Canal del Duero, el entorno de la Acequia de Tudela y Jaramiel, el entorno Duero-Canal del Duero y los paisajes y granjas de las acequias del Duero, contrasta con la endeblez de argumentos que justificaron su modificación en 2004 y 2008 para que no impidieran un tipo de operaciones urbanísticas que apenas si consideran ya las pocas infraestructuras que van quedando como meras líneas de organización territorial que deben ser convenientemente tratadas en sus márgenes. 
Agradecimientos. La presente aportación ha sido elaborada en el marco del Proyecto de Investigación Paisajes Patrimoniales de la España interior centro, septentrional y occidental, financiado por el Ministerio de Economía y Competitividad, CSO2012-39564-C07-01. Asimismo, los autores quieren manifestar su agradecimiento a Miguel Ángel Juárez Ventura, jefe del servicio técnico de la Comunidad de Regantes del Canal del Duero por la información facilitada, y a José L. García Cuesta por la elaboración de la base cartográfica.

\section{Referencias}

Bustamante, I. y Caballero, P. (coords.)(1991): El Canal del Duero, Valladolid, Junta de Castilla y León.

Borregón, A. (1880): Abastecimiento provisional de aguas en Valladolid, Revista de Obras Públicas, 28, tomo I (1):2-5.

García, J. (1974): Crecimiento y estructura urbana de Valladolid, Barcelona, Los libros de la Frontera.

García, J. (2000): Valladolid. De la ciudad a la aglomeración, Barcelona, Ariel.

Instituto de Urbanística de la Universidad de Valladolid (1988): Directrices de Ordenación Territorial de Valladolid y su Entorno, DOTV AENT. Avance, Valladolid, Junta de Castilla y León.

Junta Consultiva Agronómica (1904): El regadío en España, Madrid, Ministerio de Agricultura, Industria, Comercio y Obras Públicas.

Junta Consultiva Agronómica (1918): Medios que se utilizan para suministrar el riego a las tierras y distribución de los cultivos en la zona regable, Madrid, Imprenta de los Hijos de M.G. Hernández.

Madoz, P. (1849): Diccionario Geográfico - Estadístico - Histórico de España y sus Posesiones de Ultramar, Tomo XV, Madrid.

Rodríguez, N. (1911): Riegos del Canal del Duero, Revista de Obras Públicas, 59, tomo I (1858): 249-251. 